\title{
HOST PLANT TESTING OF THE SPITTLE BUG CARYSTOTERPA FINGENS BY STYLET PENETRATION BEHAVIOUR
}

\author{
W.R.M. SANDANAYAKA, A. CHHAGAN and P. RAMANKUTTY \\ HortResearch, Private Bag 92169, Auckland, New Zealand \\ Corresponding author: msandanayaka@hortresearch.co.nz
}

\begin{abstract}
Carystoterpa fingens (Walker) is an endemic xylem feeder. It was chosen as a model insect for the glassy winged sharp shooter (Homalodisca coagulata (Say)). The electrical penetration graph (EPG) technique was used to measure real-time stylet penetration and feeding behaviour of 48 adult $C$. fingens on four plant types, hebe (Hebe pubescens), rengarenga lily (Arthropodium cirratum), wild iris (Dietes bicolor) and cabbage (Brassica oleracea), over 12 days. EPG waveforms were recorded for 12 hours and the duration of the main penetration events (pathway, ingestion and non-probing phases) of the insects were analysed to compare host preferences. There were no significant differences in the duration of ingestion, indicating that all the plants were potential hosts for $C$. fingens. Insects on hebe showed the shortest non-probing time, suggesting that hebe was the most preferred host, as expected from observations in the wild.
\end{abstract}

Keywords: EPG, Carystoterpa fingens, probing behaviour, host plant testing.

\section{INTRODUCTION}

The New Zealand wine industry is threatened by the potential arrival of glassy winged sharp shooter (Homalodisca coagulata Say (Hemiptera: Cicadellidae); GWSS), a polyphagous xylem feeder that transmits Xylella fastidiosa, the bacterium causing Pierce's Disease in grapevines. Pierce's Disease is lethal to grapevines, and there is no cure. Information on the potential host range of GWSS in New Zealand will be important for risk assessment, surveillance and management after establishment. The refining of techniques on a related xylem-feeder already present in New Zealand may shorten the time to assess impacts on New Zealand flora if GWSS does arrive. One method of identifying preferred hosts is the electrical penetration graph (EPG) technique, which allows real-time study of probing (stylet penetration) behaviours of plant sap-sucking insects. EPG is a measurement of voltage in a circuit that contains a piercing-sucking insect and substrate (i.e. plant or artificial diet). When a gold wire-tethered insect inserts its stylets into an electrified substrate, an electrical circuit is completed. Voltage fluctuations from resistance and/or biopotentials of the insect-plant interface in the circuit are amplified and displayed on a computer monitor. These voltage fluctuations produce stereotypical waveforms that can be correlated with biological events at the plant-insect interface (Walker 2000).

EPG has been used to study many hemipteran species, including several families in the Sternorrhyncha (e.g. aphids, whiteflies and mealybugs)(Tjallingii 1990; Calatayud et al.1994; Walker \& Perring 1994), as well as Auchenorrhyncha (Backus 2000; Backus et al. 2005). These insects preferentially ingest from either phloem or xylem. Histology of probed plant tissues to identify the plant location of salivary sheaths and/ or stylet tips coupled with EPG provide a waveform correlation with the plant cell types penetrated (Tjallingii \& Hogen Esch 1993). Backus et al. (2005) identified and categorised 
stereotypical waveforms produced by $H$. coagulata during stylet penetration on grape, and correlated those waveforms with salivary sheath branch terminations in plant cells.

Following assessment of literature on New Zealand native or exotic xylem feeding leaf hoppers, spittle bugs (Hemiptera: Aphrophoridae) were selected as the best insects in New Zealand to study as a proxy for GWSS. The EPG waveforms likely to represent xylem ingestion of the introduced spittle bug Philaenus spumarius (L.) were characterised by Sandanayaka \& Charles (2006) on mahoe (Melicytus ramiflorus). Carystoterpa fingens (Walker) (Hemiptera: Aphrophoridae), a readily available endemic species with a predominantly North Island distribution and a relatively wide host range (Hamilton \& Morales 1992) was selected for the current study on four plant types. By characterising and quantifying penetration behaviour, this experiment provides further information to develop the EPG technique for comparing host preferences of xylem feeding insects.

\section{Insects and plants}

\section{MATERIALS AND METHOD}

Nymphs of $C$. fingens were field-collected from Hebe azuire and Myopolum decumbens (Plantaginaceae) and reared on potted $H$. azuire plants in cages in the laboratory at $19.5 \pm 0.5^{\circ} \mathrm{C}, 50 \pm 5 \%$ humidity and $15: 9 \mathrm{~h}$ light:dark . Three plant types with unknown status as spittlebug hosts, Arthropodium cirratum (Liliaceae) (rengarenga lily), Dietes bicolor (Iridaceae) (wild iris) and Brassica oleracea (Brassicaceae) (cabbage), and a known host Hebe pubescens, were selected for the study.

All the insects were wired using the same protocol. Young adult females were removed individually from the laboratory colony in the morning and held at $0^{\circ} \mathrm{C}$ for 8 minutes to immobilise them for wiring. One end of a $5 \mathrm{~cm}$ long piece of $20 \mu \mathrm{m}$ diameter, $99.99 \%$ gold wire was glued to a $3 \mathrm{~cm}$ long copper stub with silver conductive paint (Ladd Research Industries, USA). The other end of the gold wire was attached to the dorsum of the spittlebug with a droplet of silver paint. The end of the copper stub was then attached to the EPG amplifier. Wired insects were held for a recovery period of 10-15 minutes and then placed on the leaves of the test plants, with freedom to move within the length of the gold wire. Four insects were monitored on four plants (one of each plant type) simultaneously on four channels of the EPG monitor for 12 hours under fluorescent lights at $19.5 \pm 0.5^{\circ} \mathrm{C}$ and $50 \pm 5 \%$ humidity. This was repeated for 15 days with fresh adults and plants to give a total of 15 replicates for each plant species. Three replicates with insects that fell from the test plants were not counted and only 12 replicates were included in the analysis.

\section{EPG recording}

EPG data acquisition was with a Giga 4 EPG-DC monitor (Wageningen Agricultural University, The Netherlands) adjusted to $100 \mathrm{mV}$ with the plant electrode inserted into the soil of each test plant. Data output was digitized using a DI- 720 analogue-to digital board (DataQ ${ }^{\mathrm{TM}}$ Instruments, Akron, OH). Data acquisition, storage and real time display were performed using WinDaq ${ }^{\circledR} /$ Lite software (DataQ ${ }^{\mathrm{TM}}$ Instruments). After data acquisition, waveform categories were assigned based on stereotypical patterns. Frequencies, as well as relative and absolute amplitudes of waveforms, were also measured. Duration measurements for each waveform event (i.e. a continuous, uninterrupted occurrence of one waveform type) were made with WinDaq ${ }^{\circledR} /$ Lite Browser software. These files were copied into a Microsoft ${ }^{\circledR}$ Excel workbook for statistical analysis.

The current study followed the terminology conventions of Backus (2000). A probe is defined as all behaviours occurring from start of stylet penetration into plant tissue until stylet withdrawal.

\section{Statistical analysis}

Plant types were assigned to the treatments in a completely randomised design. The data were analysed by a form of analysis of variance known as robust regression. The model assumes that the error terms are normally and identically distributed with zero mean and constant variances. Unlike ordinary least squares regression or standard analysis of variance, robust regression is more resistant to extreme values and departures 
from normality. The $\mathrm{P}$ values reported in this analysis have been obtained using one of the approved methods for calculating significance of effects in robust regression analysis.

The analysis was conducted using R (R Development Core Team 2006). Means separation tests were carried out using a Least Significant Difference calculated from the residual mean squares at the 5\% level of significance. Various plots (scatter plots, histograms and normal probability plots) of the residuals were examined to ensure that the model assumptions were met.

\section{RESULTS}

An example EPG of $C$. fingens on $H$. pubescens is shown in Figure 1a. Eleven distinctively different EPG waveform types were observed (Fig. 1b) throughout the experiments. These were labelled as follows:

A - start of the probe, high amplitude insertion spike representing deep stylet drilling

B1 - occasional high peaks and low valleys with or without irregular spikes

B2 - more frequent irregular spikes, in wave-like peaks

$\mathrm{C}$ - regular waveforms representing ingestion, accompanied by excretory droplets

$\mathrm{C} 0$ - regular ' $\mathrm{C}$ ' waves in between straight lines

D1 - waveforms with single spikes, produced infrequently

$\mathrm{D} 2$ - similar to B2 waveforms, occur in between 'C' waves (interruptions)

$\mathrm{F}$ - regular, low amplitude waveforms

$\mathrm{G}$ - straight line with spiky waves in between

$\mathrm{L}$ - straight line, no relative amplitude variation

$\mathrm{W}$ - wavy line.

The waveforms were categorised into three main phases. These were:

(1) Non-probing phase that corresponded to the baseline, and was correlated visually with walking and resting of the insect. Relative amplitude was variable but usually low $(0-25 \%)$.

(2) Pathway phase that always started with "A" immediately after a non-probing phase. All the waveforms except $\mathrm{C}$ and $\mathrm{C} 0$ were included in the pathway phase, and it is assumed that they all represented various activities occurring during stylet penetration of plant tissues.

(3) Ingesting phase that was represented by $\mathrm{C}$ and $\mathrm{C} 0$ waveforms. Excretory droplets were usually observed during long probes where continuous $\mathrm{C}$ or $\mathrm{C} 0$ waveforms occurred for more than 4-5 minutes.

Differences in settling behaviour of $C$. fingens on test plant types were observed. Of the total of 60 insects tested, all those on $A$. cirratum and $H$. pubescens remained on the plants for the whole 12 hours of the recording period. On D. bicolor and B. oleracea, $10 \%$ and $20 \%$ of the insects respectively moved away from the plants during the recordings and they were not included in the analysis. All the spittlebugs tested showed ingestion (C and $\mathrm{C} 0$ waveforms) except two individuals on $D$. bicolor, which terminated probing (stylets withdrawn) before reaching xylem. However, the total duration spent in the ingesting phase was not significantly different between the four plant types (Table 1).

The numbers of probes observed from individual insects during the 12 hours access time varied from 1-109, but did not differ significantly between the four plant types. However, total non-probing periods of the insects on plant types were significantly different $(\mathrm{P}=0.024)$. The shortest and the longest non-probing times were recorded on $H$. pubescens and $D$. bicolor respectively. Insects on $H$. pubescens spent significantly more time on the activities represented by A + B1 waveforms (Table 1). 
(a)

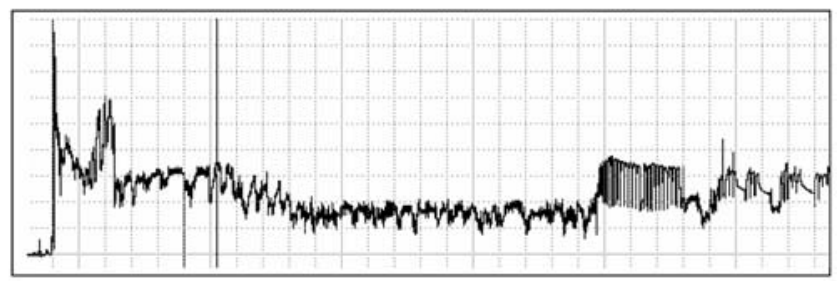

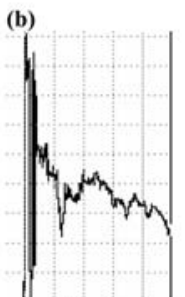

A

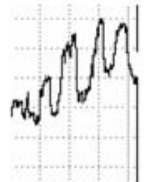

B1

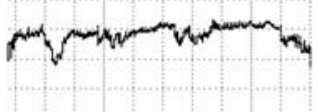

B2

\section{rervorirer}

C
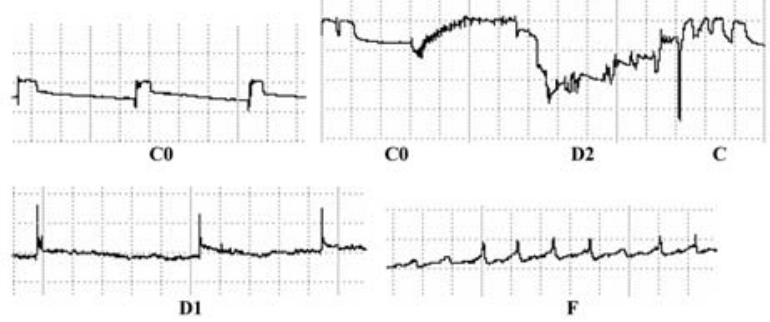

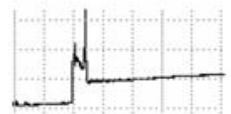

G

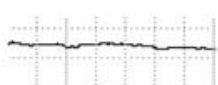

L

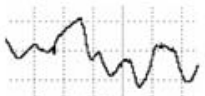

W

FIGURE 1: Electrical penetration graph of Carystoterpa fingens on Hebe pubescens leaves. (a) Overview of the first 3 minutes from the start of stylet penetration (8 seconds duration in each square). (b) The 11 distinctively different EPG waveform types seen during all of the experiments ( 2 seconds duration in each square). 
TABLE 1: The estimated mean total duration (min) (and SE in parentheses) of each electrical penetration graph (EPG) waveform types. Also shown is the estimated mean number of probes for Carystoterpa fingens probing on four plant species.

\begin{tabular}{cccccc}
\hline Waveform types & $\begin{array}{c}\text { Arthropodium } \\
\text { cirratum }\end{array}$ & Dietes bicolor & $\begin{array}{c}\text { Brassica } \\
\text { oleracea }\end{array}$ & $\begin{array}{c}\text { Hebe } \\
\text { pubescens }\end{array}$ & P-value \\
\hline $\begin{array}{c}\text { Non-probing phase } \\
\text { Np }\end{array}$ & $163.4(85.0) \boldsymbol{d}$ & $329.4(85.0) \boldsymbol{c}$ & $281.1(60.1) \boldsymbol{b}$ & $88.6(85.0) \boldsymbol{a}$ & $0.024^{1}$ \\
$\begin{array}{c}\text { Pathway phase } \\
\text { A+B1 }\end{array}$ & $7.9(7.9) \boldsymbol{b}$ & $6.0(7.9) \boldsymbol{b}$ & $15.5(5.6) \boldsymbol{b}$ & $122.5(7.9) \boldsymbol{a}$ & $<0.001$ \\
$\mathrm{~B} 2$ & $35.4(10.5)$ & $11.7(10.5)$ & $16.4(7.4)$ & $51.1(10.5)$ & 0.252 \\
$\mathrm{D} 1$ & $0.2(0.2)$ & $0.0(0.2)$ & $0.2(0.1)$ & $0.2(0.2)$ & 0.999 \\
$\mathrm{D} 2$ & $6.3(2.1)$ & $7.3(2.1)$ & $6.1(1.5)$ & $13.7(2.1)$ & 0.130 \\
$\mathrm{~F}$ & $0.1(0.2)$ & $0.1(0.2)$ & $0.2(0.1)$ & $0.6(0.2)$ & 0.999 \\
$\mathrm{G}$ & $0.6(0.3)$ & $0.0(0.3)$ & $0.4(0.2)$ & $0.3(0.3)$ & 0.998 \\
$\mathrm{~L}$ & $7.3(6.4)$ & $4.3(6.4)$ & $7.7(4.5)$ & $26.2(6.4)$ & 0.755 \\
$\mathrm{~W}$ & $1.0(2.1)$ & $0.8(2.1)$ & $3.4(1.5)$ & $9.0(2.1)$ & 0.967 \\
Ingestion phase & & & & & \\
$\mathrm{C}$ & $423.7(92.9)$ & $329.3(92.9)$ & $258.1(65.7)$ & $417.0(92.9)$ & 0.206 \\
C0 & $2.4(1.01)$ & $2.0(1.1)$ & $0.2(0.8)$ & $0.1(1.1)$ & 0.999 \\
Mean no. probes & $11.2(3.7)$ & $9.5(3.7)$ & $13.5(2.6)$ & $13.9(3.7)$ & 0.937 \\
\hline
\end{tabular}

${ }^{1}$ Values in the same row with the same letters indicate that the means are not statistically different at $\alpha=0.05$.

\section{DISCUSSION}

Feeding is one of the main activities assessed when testing insect host plant preferences, and real feeding (ingesting) time recorded by EPG may potentially provide an indication of host preferences of sucking insects. In this trial, there was no difference in the duration of ingestion on any of the host plants, suggesting that all four species tested are potential hosts of $C$. fingens.

The settling behaviour of insects on plants is also an important component of host plant choice, as feeding can not occur until insects settle. In EPG testing, the potential feeding area is constrained by the length of the wire. If the plant is not accepted by the insect, little or no time is spent on ingestion and instead, the insect attempts to escape from the experimental arena. These types of behaviours were apparent in the current study and were primarily observed with insects on $D$. bicolor and $B$. oleracea. The difference in settling behaviour of the spittle bugs on four plant types suggests that $A$. cirratum and $H$. pubescens are more acceptable hosts than $D$. bicolor and B. oleracea. The differences in non-probing time across the plant species may also show the expression of host preference of $C$. fingens.

Researchers have reported that waveform durations, appearances and waveform progression differ when insects probe into different tissues of the plants (Backus et al. 2000; Tjallingii \& Hogen Esch 1993). Similar types of EPG waveforms to those shown in this study were observed for GWSS probing on grape petiole, and histological correlations for many of those waveforms have been made using both light and transmission electron microscopy (Backus et al. 2005). The regular, squared valley-and-plateau C waveform has been correlated with xylem sap ingestion in GWSS (Backus et al. 2005) and blue-green 
sharp shooter, Graphocephala atropunctata (Say) (Hemiptera, Cicadellidae) (Almeida \& Backus 2004), which most likely relates to the rhythmic muscular contraction of the cibarial dilator muscles (cibarial pumping) during continuous ingestion. Crane (1970) observed a similar, regular pattern of rhythmic suction in G. atropunctata. Such suction is the ingestion strategy for many Auchenorrhyncha, because active ingestion waveforms often show highly regular, rhythmic series of peaks or plateaux (Lett et al. 2001).

This research is the first investigation of the stylet penetration behaviour of $C$. fingens. EPG has proved to be a powerful tool for quantifying stylet penetration behaviour of homopteran insects when comparing the feeding activity on different host plants. It has allowed statistical comparisons and contributed towards the development of techniques to assess the host range of newly encountered sap- feeding insects. Such quantification may aid in development of rapid screening of the host range of GWSS if it arrives in New Zealand.

\section{ACKNOWLEDGMENTS}

We express our thanks to John Charles, David Logan and Anne Gunson (HortResearch) and Pip Gerard (AgResearch) for their valuable comments. This research was funded by New Zealand's Foundation for Research, Science and Technology through the Better Border Biosecurity (B3) Programme (www.b3nz.org).

\section{REFERENCES}

Almeida RPP, Backus EA 2004. Stylet penetration behaviors of Graphocephala atropunctata (Say): EPG waveform characterisation and quantification. Annals of the Entomological Society of America 97: 838-851.

Backus EA 2000. Our own jabberwocky: clarifying the terminology of certain piercingsucking behaviors of homopterans. In: Walker GP, Backus EA ed. Principles and applications of electronic monitoring and other techniques in the study of homopteran feeding behavior. Thomas Say Publications in Entomology, Entomological Society of America, Lanham, MD, USA. Pp. 1-13.

Backus EA, Devancy MJ, Bennet WH 2000. Comparison of signal processing circuits among seven AC electronic monitoring systems for their effects on the emf and R components of aphid waveforms. In: Walker GP, Backus EA ed. Principles and applications of electronic monitoring and other techniques in the study of homopteran feeding behavior. Thomas Say Publications in Entomology, Entomological Society of America, Lanham, MD, USA. Pp. 102-143.

Backus EA, Habibi J, Yan FM, Ellersieck M 2005. Stylet penetration by adult Homalodisca coagulata on grape: Electrical penetration graph waveform characterization, tissue correlation, and possible implications for transmission of Xylella fastidiosa. Annals of the Entomological Society of America 98(6): 787-813.

Calatayud PA, Rahbe Y, Tjallingii WF, Tertuliano M, Ru BL 1994. Electrically recorded feeding behaviour of cassava mealybug on host and non-host plants. Entomologia Experimentalis et Applicata 72: 219-232.

Crane PS 1970. The feeding of the blue-green sharp shooter Hordnia circellata (Baker) (Homoptera: Cicadellidae). Ph. D. thesis, University of California, Davis, CA, USA.

Hamilton KGA, Morales CF 1992. Cercopidae (Insecta:Homoptera) Fauna of NZ series 25. DSIR Plant Protection, Auckland, New Zealand. Pp. 13-14.

Lett JM, Granier M, Grondin M, Turpin P, Molinaro F, Chiroleu F, Peterschmitt M, Reynaud B 2001. Electrical penetration graphs from Cicadulina mbila on maize, the fine structure of its stylet pathways and consequences for virus transmission efficiency. Entomologia Experimentalis et Applicata 101: 93-109.

Sandanayaka WRM, Charles JG 2006. EPG as a tool for host plant screening? New Zealand Plant Protection 59: 364 (Abstract only).

R Development Core Team 2006. R: A language and environment for statistical computing. R Foundation for Statistical Computing, Vienna, Austria (http://www. R-project.org). 
Tjallingii WF 1990. Continuous recording of stylet penetration activities by aphids. In: Campbell RK, Eikenbary RD ed. Aphid-Plant Genotype Interaction. Oklahoma, USA. Pp. 89-99.

Tjallingii WF, Hogen Esch TH 1993. Fine structure of aphid stylet routes in plant tissues in correlation with EPG signals. Physiological Entomology 18: 317-328.

Walker GP, Perring TM 1994. Feeding and oviposition behavior of whiteflies (Homoptera: Aleyrodidae) interpreted from AC electronic feeding monitor waveforms. Entomological Society of America 87(3): 363-374.

Walker GP 2000. A beginner's guide to electronic monitoring of homopteran probing behavior. In: Walker GP, Backus EA ed. Principles and applications of electronic monitoring and other techniques in the study of homopteran feeding behavior. Thomas Say Publications in Entomology, Entomological Society of America, Lanham, MD, USA. Pp. 14-40. 